\title{
Alterations of Arbuscular Mycorrhizal Fungal Diversity in Soil with Elevation in Tropical Forests of China
}

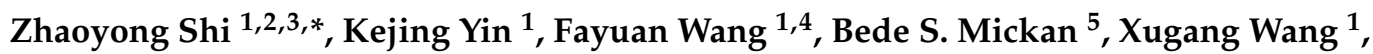 \\ Wenli Zhou ${ }^{1}$ and Yajuan $\mathrm{Li}^{1}$ \\ 1 College of Agriculture, Henan University of Science and Technology, Luoyang 471023, China; \\ wzjbnbxxx@163.com (K.Y.); wangfayuan@qust.edu.cn (F.W.); nywxg@126.com (X.W.); \\ zwli12@163.com (W.Z.); liyajuan207@163.com (Y.L.) \\ 2 Laboratory of Earth Surface Processes of the Ministry of Education, Peking University, Beijing 100871, China \\ 3 Luoyang Key Laboratory of Symbiotic Microorganism and Green Development, Luoyang 471023, China \\ 4 College of Environment and Safety Engineering, Qingdao University of Science \& Technology, \\ Qingdao 266042, China \\ 5 Richgro Garden Products, 203 Acourt Rd, Jandakot, Western Australia 6164, Australia; \\ bedemickan@gmail.com \\ * Correspondence: shizy1116@126.com
}

Received: 2 August 2019; Accepted: 16 September 2019; Published: 1 October 2019

check for updates

\begin{abstract}
Mycorrhizas play a vital role in ecosystem function, diversity and productivity. However, mycorrhizas in tropical forests are considered to be a neglected area of research in contrast to the well-studied diversity patterns of macro organisms. To this end, soil samples from 0 to $30 \mathrm{~cm}$ in depth were collected from six or four elevations in a typical tropical forest of Mt. Jianfeng and Mt. Diaoluo in China. The arbuscular mycorrhizal fungal (AMF) diversity and community composition were explored among different elevations based on high-throughput barcoded sequencing on the Illumina MiSeq platform. Environmental variables of soil characteristics, and elevation on AMF community assembly were analyzed using canonical correspondence analysis. In total, $316 \mathrm{AMF}$ operational taxonomic units (OTUs) were found to belong to four identified and one unclassified order, and Glomus was the most dominant genus in tropical forest. AMF communities or diversity did not clearly reflect local environmental conditions, the spatial distance between mountains and elevation. In total, $68 \%$ and $56 \%$ of taxa of AMF were observed on multiple elevations in Mt. Jianfeng and Mt. Diaoluo, respectively. Furthermore, $8.9 \%$ and $19 \%$ of OTUs were exhibited on all elevations in Mt. Jianfeng and Mt. Diaoluo, respectively. The AMF alpha diversity, richness and evenness were similar across the two surveyed tropical mountains. The influence of elevation showed no distinct role on the diversity of AMF taxa. Overall, AMF communities and diversity are abundant in tropical forests and with little influence of elevation in tropical forests of China.
\end{abstract}

Keywords: arbuscular mycorrhizal fungi; diversity; community composition; elevational gradient; tropical forest

\section{Introduction}

As a ubiquitous group of soil fungi, arbuscular mycorrhizal fungi (AMF) can form obligate symbioses with 70-90\% of land plants; furthermore, they are involved in the cycling of nutrients and can also aid in the protection against abiotic stresses of host plants [1,2]. AMF diversity has been associated with plant community diversity, structure and ecosystem function [3-5]. Therefore, the research into 
AMF communities and diversity has been conducted in the global ecosystem [6] and across many ecosystems, such as forest [7], grassland [8], and agro-ecosystems [9].

Tropical forests are broadly considered to harbor the greatest amount of global biodiversity, productivity and terrestrial carbon stocks, which is a vital a process driving global climate, disease control, and also pollination [10]. However, the response of tropical forests and the subsequent feedback of global climatic changes are likely to be significant at the regional scale [11]. AMF are widely considered to be the dominant mycorrhizal type in tropical ecosystems [12,13] and are widely claimed to play a fundamental role in nutrient uptake and the composition of tree regeneration [14]. Many studies on AMF composition and diversity have focused on ascertaining their status and identifying the driving forces in tropical mountains; however, these studies did not identify the role and importance of AMF in tropical forest ecosystems [15,16].

Mountain ecosystems provide a unique opportunity to explore the interactions between soil microbes and plant performance along strong environmental gradients to understand driving forces contributing to species assemblages [17]. Ecologists have focused on the patterns of individual taxa and the community composition in response to elevational gradients based on the distribution of biodiversity at different elevations [18].

To ascertain the resources and changes of AM fungal communities or diversity along altitudinal gradients in tropical ecosystems, we studied AMF community composition and diversity based on typical tropical forests with the most integral tropical vegetation and the most abundant plant biodiversity sites from Mt. Jianfeng and Mt. Diaoluo in China. The objectives of the present study were to address (i) the AMF community composition or diversity at the molecular level and (ii) the correlations between the AMF community or diversity and the elevation gradient and soil parameters.

\section{Materials and Methods}

\subsection{Study Site and Sample Collection}

This study was conducted on Mt. Jianfeng $\left(108^{\circ} 46^{\prime}-109^{\circ} 45^{\prime}\right.$ E, $\left.18^{\circ} 23^{\prime}-18^{\circ} 50^{\prime} \mathrm{N}\right)$ and Mt. Diaoluo $\left(109^{\circ} 41^{\prime} 38^{\prime \prime}-110^{\circ} 4^{\prime} 46^{\prime \prime} \mathrm{E}, 18^{\circ} 38^{\prime} 42^{\prime \prime}-18^{\circ} 50^{\prime} 22^{\prime \prime} \mathrm{N}\right)$ on Hainan Island in southern China. Mt. Jianfeng is the largest and best-preserved tropical rainforest in China. The forest surpasses the Amazon, the Congo River and Southeast Asian tropical rainforests in terms of the integrity of the vegetation and species diversity. Mt. Diaoluo is also the best preserved and most integrated tropical forest, with a forest coverage rate of $86.6 \%$.

Soil samples were collected from six elevational gradients of $350 \mathrm{~m}, 600 \mathrm{~m}, 800 \mathrm{~m}, 1000 \mathrm{~m}, 1200 \mathrm{~m}$, and $1350 \mathrm{~m}$ above sea level (a.s.l.) at Mt. Jianfeng and four elevational gradients of $250 \mathrm{~m}, 450 \mathrm{~m}, 660 \mathrm{~m}$, and $930 \mathrm{~m}$ a.s.l. at Mt. Diaoluo, respectively. Sample belts were set for each elevation. With each sample belt, three $20 \times 20 \mathrm{~m}$ plots were placed 50-100 m horizontally apart from each other. Each plot was divided into $100 \mathrm{~m}$ with $2 \times 2 \mathrm{~m}$ subplots. One hundred $0-30 \mathrm{~cm}$ soil cores with a diameter of $5 \mathrm{~cm}$ were collected at the center of each subplot. The 100 soil cores were then combined to form one mixed sample for each plot. Subsamples of a soil mix (approximately $50 \mathrm{~g}$ ) were randomly collected and stored in a cooling bin containing dry ice before being transported to a local laboratory to assess AM fungal diversity. A total of 30 samples was collected from the tropical forests of Hainan island.

\subsection{Analyses of Soil Parameters}

All 30 soil samples were analyzed in triplicate. Soil $\mathrm{pH}$ was determined with a glass electrode with a ratio of soil to distilled water of 1:2.5; soil total carbon (C) and total nitrogen $(\mathrm{N})$ were measured by an elementar vario MACRO cube analyzer (Elementar Analysensysteme, GmbH, Germany) [19,20], and total phosphorus $(\mathrm{P})$ was assessed with sodium hydroxide fusion and the Mo-Sb spectrophotometric method [21]. 


\subsection{DNA Extraction and PCR Amplification}

Microbial genomic DNA was extracted from soil samples using the FastDNA SPIN Kit for Soil (MP Biomedicals LLC, Santa Ana, CA, USA) according to the manufacturer's protocols. The final DNA concentration and purification were determined by NanoDrop 2000 UV-vis spectrophotometer (Thermo Scientific, Wilmington, NC, USA), and DNA quality was checked by $1 \%$ agarose gel electrophoresis. The extracted DNA was subjected to nested PCR by Thermocycler PCR system (GeneAmp 9700, ABI, Carlsbad, CA, USA). The first PCR amplification was performed with primers AML1F (5'-ATCAACTTTCGATGGTAGGATAGA-3') and AML2R (5'-GAACCCAAACACTTTGGT TTCC $\left.-3^{\prime}\right)$. The PCR reactions were conducted using the following program: $3 \mathrm{~min}$ of denaturation at $95{ }^{\circ} \mathrm{C}, 32$ cycles of $30 \mathrm{~s}$ at $95^{\circ} \mathrm{C}, 30 \mathrm{~s}$ for annealing at $55^{\circ} \mathrm{C}$, and $45 \mathrm{~s}$ for elongation at $72{ }^{\circ} \mathrm{C}$, and a final extension at $72{ }^{\circ} \mathrm{C}$ for $10 \mathrm{~min}$. PCR reactions were performed in triplicate with the $20 \mu \mathrm{L}$ mixture containing $4 \mu \mathrm{L}$ of $5 \times$ FastPfu Buffer, $2 \mu \mathrm{L}$ of $2.5 \mathrm{mM}$ dNTPs, $0.8 \mu \mathrm{L}$ of each primer $(5 \mu \mathrm{M}), 0.4 \mu \mathrm{L}$ of FastPfu Polymerase, and $10 \mathrm{ng}$ of template DNA. The second PCR amplication used identical reaction conditions described above with the primers AMV4-5NF (5'-AAGCTCGTAGTTGAATTT CG-3') and AMDGR ( $5^{\prime}$-CCCAACTATCCCTATTAATCAT- $\left.3^{\prime}\right)$, and the following program: 3 min of denaturation at $95{ }^{\circ} \mathrm{C}, 30$ cycles of $30 \mathrm{~s}$ at $95{ }^{\circ} \mathrm{C}, 30 \mathrm{~s}$ for annealing at $55^{\circ} \mathrm{C}$, and $45 \mathrm{~s}$ for elongation at $72{ }^{\circ} \mathrm{C}$, and a final extension at $72{ }^{\circ} \mathrm{C}$ for $10 \mathrm{~min}$. The resulted PCR products were extracted from a $2 \%$ agarose gel and further purified using the AxyPrep DNA Gel Extraction Kit (Axygen Biosciences, Union City,

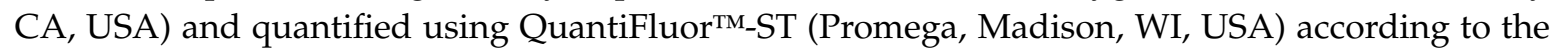
manufacturer's protocol.

Purified amplicons were pooled in equimolar and paired-end sequenced $(2 \times 250)$ on an Illumina MiSeq platform (Illumina, San Diego, CA, USA) according to the standard protocols by Majorbio Bio-Pharm Technology Co. Ltd. (Shanghai, China).

\subsection{Processing of Sequencing Data}

Operational taxonomic units (OTUs) were clustered with $97 \%$ similarity cutoff using UPARSE (version 7.1) [22] and chimeric sequences were identified and removed using UCHIME. The taxonomy of each gene sequence was analyzed by RDP Classifier algorithm [23] against the MaarjAM database using a confidence threshold of $70 \%$.

\subsection{Data Analysis}

AMF taxa between Mt. Diaoluo and Jiangfeng and among different elevations were analyzed based on the OTU level, which was presented by Venn diagrams. The community composition was calculated by the percent of community abundance according to the average of OTU abundance of each OTU with the combination of less than $1 \%$ abundance of OTUs in different elevations of two mountains. AMF community richness, evenness and diversity were expressed by the index of sobs, shannoneven and Shannon based on AMF OTU level, respectively [24,25]. Canonical correspondence analysis (CCA) was employed for exploring the relationships between AMF community and environmental variables at the level of $p \leq 0.05$ and $p \leq 0.01$, respectively. The differences between two mountains and among different elevations were analyzed by Duncan test in SPSS 19.0. The CCA analyses are conducted in bioinformatics analysis cloud platform of MajorBio Cloud [26].

\section{Results}

\subsection{AMF Community Composition and Distribution in Tropical Forest of China}

A total of 316 OTUs belonging to Glomeromycota were detected in two mountains of tropical forest (Figure 1A). Two mountains were considered, 261 and 236 OTUs were detected in Mt. Diaoluo and Jianfeng, respectively. One-hundred-and-eighty-one OTUs were shared by two mountains. Endemic OTUs of 80 and 55 were identified in Mt. Diaoluo and Jianfeng, respectively. AMF OTUs changed from 80 to 143 with an average of 109.7 in six different elevations in Mt. Jianfeng, and from 
103 to 173 with an average of 138.4 in four different elevations in Mt. Diaoluo (Figure 1B,C). Of OTUs in two mountains, $160(68 \%)$ and 146 (56\%) OTUs were shared by more than one elevation in Mt Jianfeng and Mt. Diaoluo, respectively (Figure 1).

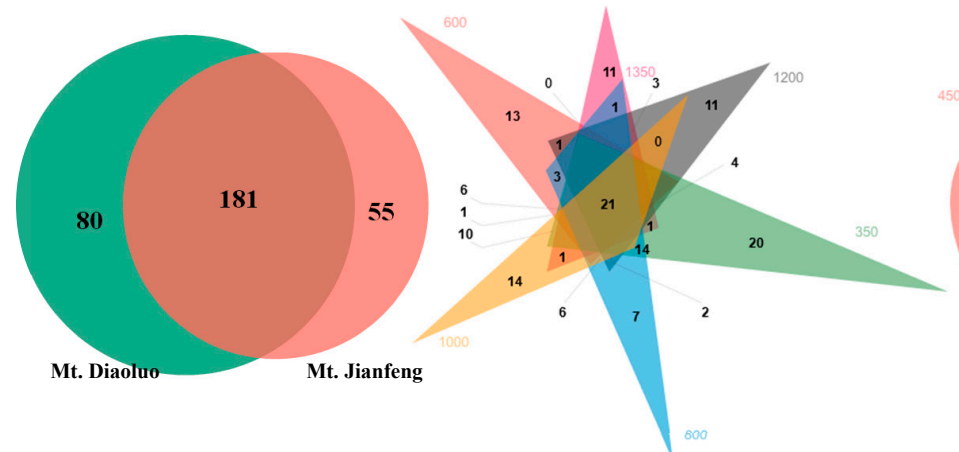

(A)
(B)

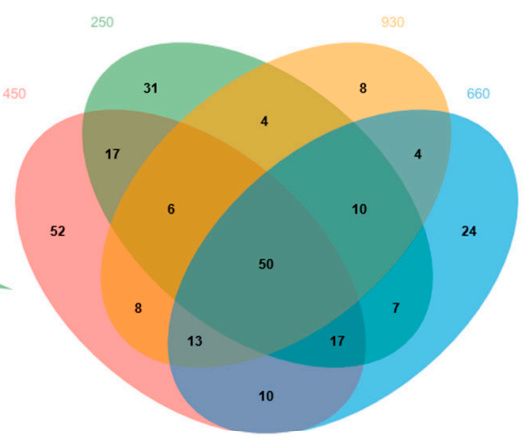

(C)

Figure 1. Venn diagrams (using relevant subsets of the full data set) showing the sharing of arbuscular mycorrhizal (AM) fungal OTUs (operational taxonomic units) between two mountains (A) and among different elevations in Mt. Jianfeng (B) and Mt. Diaoluo (C) in the tropical forest of China.

AMF communities were presented by the percent of community abundance on OTUs with an integration of less than $1 \%$ OTUs in different mountains and elevations (Figure 2). The most abundant OTU is OTU114 and OTU190 with abundances of $8.4 \%$ and $9.3 \%$ in Mt. Diaoluo and Jianfeng, respectively (Figure 2A). In Mt. Diaoluo, the highest abundance of AMF OTU changes from $10.5 \%$ to $18.8 \%$ among four elevations (Figure 2B). The change of the most abundant AMF OTU is from $8.7 \%$ (OTU280) in a.s.l. $600 \mathrm{~m}$ to $38.4 \%$ (OTU190) in a.s.l. $1200 \mathrm{~m}$ in Mt. Jianfeng (Figure 2C).
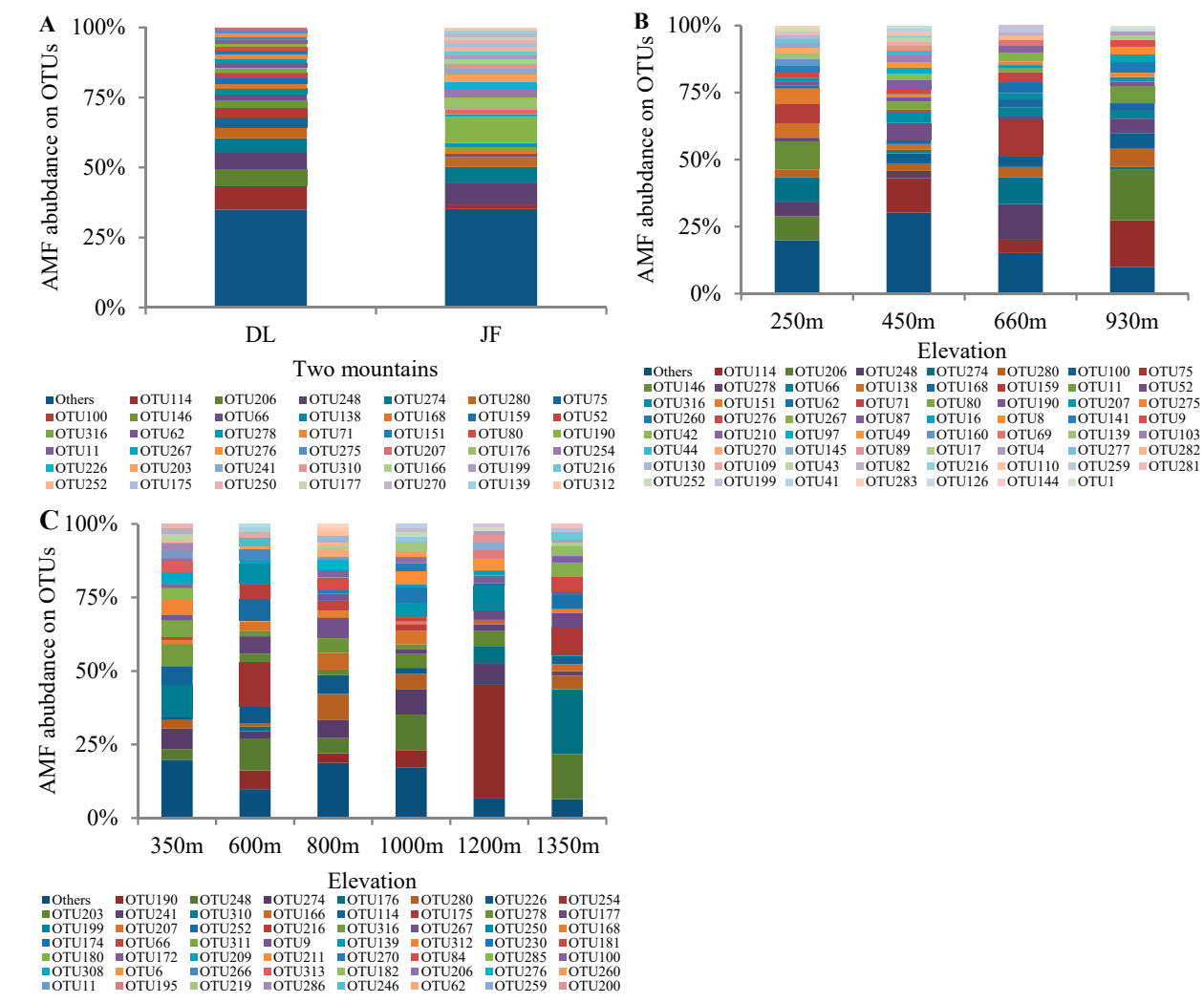

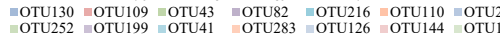

Figure 2. AM fungal communities in two mountains (A) and among different elevations in Mt. Diaoluo (B) and Mt. Jianfeng (C) in the tropical forest of China. DL and JF mean Mt. Diaoluo and Mt. Jianfeng. 
AMF belonged to four identified orders including Archaeosporales (10 OTUs), Diversisporales (51 OTUs), Glomerales (218 OTUs), and Paraglomerales (3 OTUs), and one unclassified order (34 OTUs) (Table 1). The genera of Glomus is the dominant genus with 218 OTUs, which accounts for the total number of $69 \%$.

Table 1. Arbuscular mycorrhizal fungal OTU number in different order, family and Genera in Mt. Jianfeng (JF) and Mt. Diaoluo (DL).

\begin{tabular}{cccccc}
\hline \multirow{2}{*}{ Order } & \multirow{2}{*}{ Family } & Genus & \multicolumn{2}{c}{ Number of OTUs } & \multirow{2}{*}{ Total OTUs } \\
\cline { 3 - 4 } & & & Mt. JF & Mt. DL & \\
\hline \multirow{3}{*}{ Archaeosporales } & Ambisporaceae & Ambispora & 1 & 1 & 1 \\
& & 3 & 5 & 6 \\
& & Archaeospora & 2 & 2 & 2 \\
& Unclassified & & 1 & 18 & 1 \\
& Acaulosporaceae & Acaulospora & 13 & 1 & 7 \\
Diversisporales & Diversisporaceae & Diversispora & 6 & 2 & 2 \\
& & Unclassified & 1 & 13 & 16 \\
Glomerales & Gigasporaceae & Scutellospora & 15 & 6 & 7 \\
Paraglomerales & Paraglomeraceae & Paraglomus & 2 & 1 & 218 \\
unclassified & & Glomified & 5 & 16 & 3 \\
\hline
\end{tabular}

\subsection{AMF Diversity between Different Mountains and among Different Elevations in Tropical Forest of China}

The community richness, evenness and diversity of AMF were not significantly different between two mountains in tropical forest soil based on OTU level, which is based on the index of sobs, shannoneven and Shannon, respectively (Figure 3). The highest richness, diversity and evenness of AMF were observed in a.s.1. $800 \mathrm{~m}$ in Mt. Jianfeng (Figure 4). The AMF diversity were significantly higher in a.s.1. $800 \mathrm{~m}$ than those in a.s.1. $1350 \mathrm{~m}$ (Figure 4A,B). At the same time, the AMF richness in a.s.1. 1200 and $1350 \mathrm{~m}$ was also remarkably lower than in a.s.1. $800 \mathrm{~m}$ and a.s.1. $1000 \mathrm{~m}$, respectively (Figure 4A). In addition, there are no significant differences among other elevations for either the community richness or diversity in Mt. Jianfeng (Figure 4A,B). As far as the different elevations were concerned, AMF community richness, evenness and diversity were similar among all elevations in Mt. Diaoluo (Figure 4D-F).
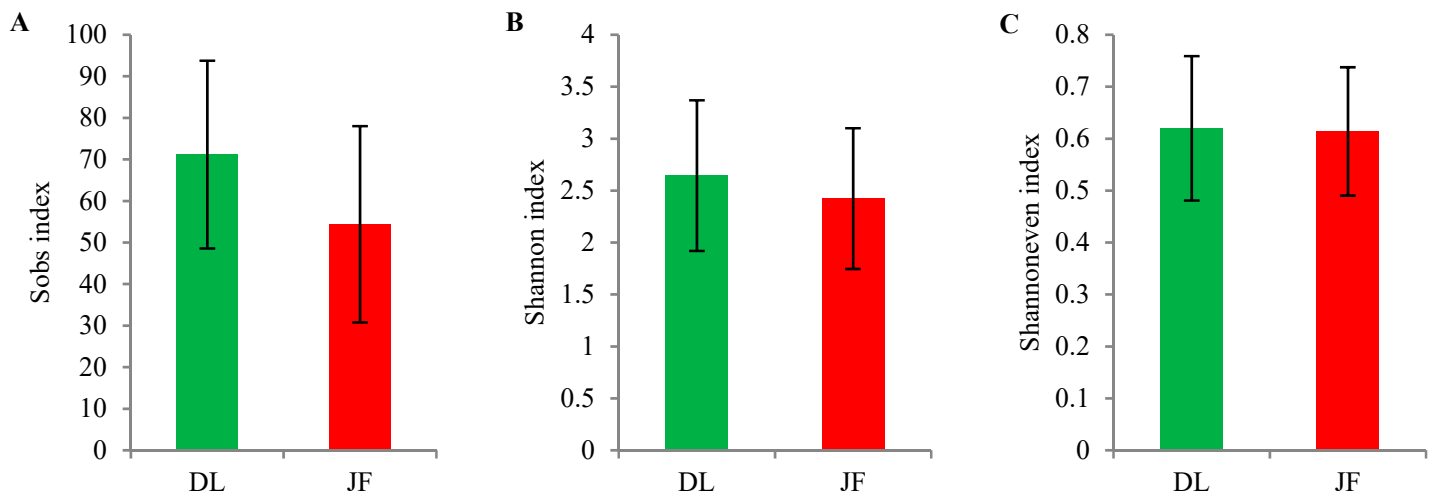

Figure 3. The comparision of AM fungal diversity including sobs (A), Shannon (B) and Shannoneven index (C) based on the level of OTUs in two mountains in the tropical forest of China. Each column represents the mean value and bar standard deviation. DL and JF mean Mt. Diaoluo and Mt. Jianfeng. 

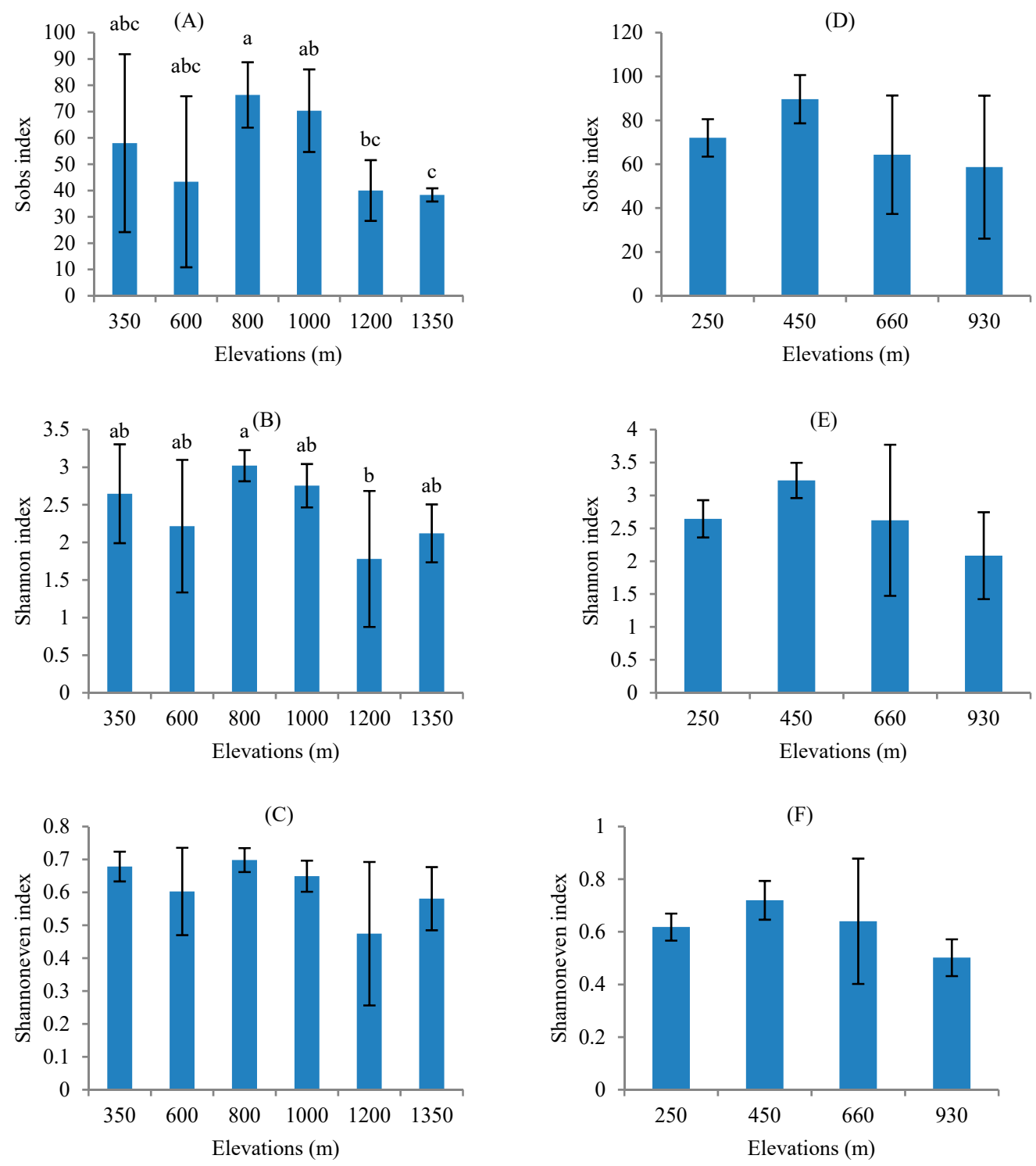

Figure 4. The comparision of AM fungal diversity based on the level of OTUs among different elevations of Mt Jianfeng (A-C) and Mt. Diaoluo (D-F) in the tropical forest of China. Each column represents the mean value and bar standard deviation. The different lowercase letters above the bars represent significant differences across elevations at the level of $p \leq 0.05$.

\subsection{Contribution of Environmental Factors to AMF Diversity in Tropical Forest of China}

The significance of elevation and soil parameters including $C, N, P, C: P, N: P, C: N$, and $p H$ for the AMF community composition was explored using CCA (Figure 5). Elevation and soil C, N, C:P have significant effects on the AMF diversity in two mountains (Figure 5A). Individual environmental factors accounted for between 1.7\% (soil total $\mathrm{P}$ ) and 93.3\% (soil total $\mathrm{C}$ ) of the variation in AMF diversity in two tropical mountains (Figure 5A). The AMF diversity was not affected by elevation and seven soil factors across four elevations in Mt. Diaoluo (Figure 5B). In Mt. Jianfeng, five out of eight environment factors including elevation and soil C, N, C:P, N: P remarkably affected the AMF community along elevations with the explanation rate from $62.7 \%$ to $93.0 \%$ for AMF community variation (Figure 5C). 

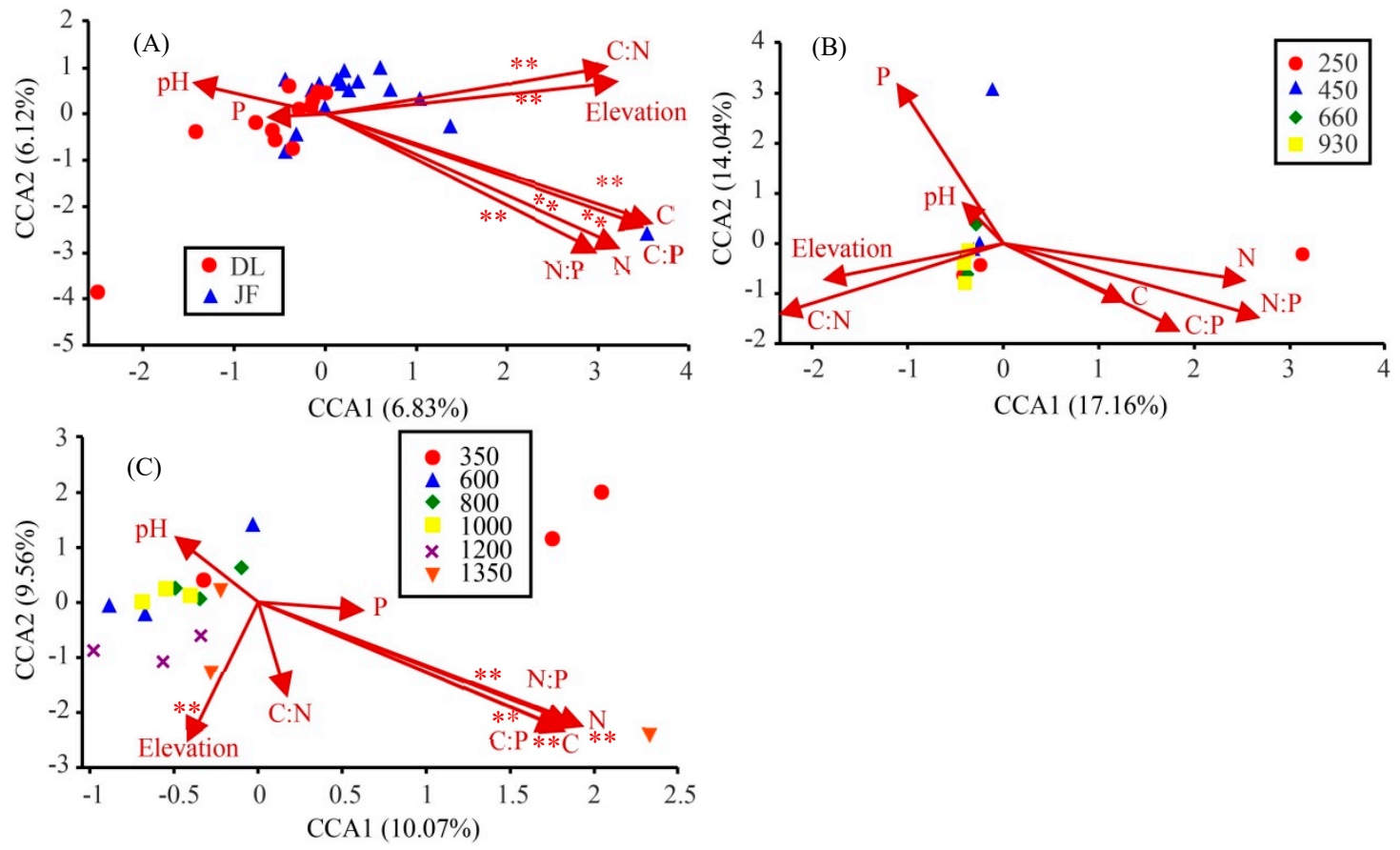

Figure 5. The influence of environmental factors on AM fungal communities based on the canonical correspondence analysis (CCA) in two different mountains (A) and different elevations of Mt. Diaoluo (B) and Mt. Jiangfeng (C) in tropical forest of China. The ${ }^{* *}$ means the significant effect at the level of $p \leq 0.01$.

\section{Discussion}

Alexander and Selosse (2009) reported that mycorrhizas in tropical forests are a neglected area of research [14]. In this study, we explored the diversity of AMF in the tropical forest of China, and to ensure an accurate assessment of diversity across tropical forests, we used two mountains of Mt Diaoluo and Jianfeng at the same latitudes as suitable sites. AMF were detected in two tropical mountains with 316 OTUs (Figure 1A) compared with 350 to 1000 molecularly defined AMFs in the global land ecosystem [27], which is also higher than has been previously observed in molecular surveys in different global ecosystems [6]. This result is generally accepted as tropical forests have a higher biodiversity, which is also reflected by the increase in plant diversity. AMF is obligated to associate with living plant roots and is widely claimed to not be host-specific [1]. Therefore, studies have reported that high AMF diversity is usually along with high plant diversity. This low endemism or high shared taxa of AMF between Mt. Diaoluo and Jianfeng and among elevations in two mountains supports the conclusion that a global assessment of AMF diversity reveals very low endemism or high shared taxa made by Davison et al. (2015), which showed that $93 \%$ of the AMF taxa are presented in multiple continents and $34 \%$ in six global continents [6].

Alpha diversity indicators of AMF as assessed by species richness, diversity and evenness, displayed no differences between the two surveyed tropical mountains, which might be explained by the following reasons. Firstly, the results showed that the detection of the number of AMF OTUs in the two mountains may be credible because the numbers of AMF OTUs does not increase with sampling effort in Mt. Jianfeng as compared to Mt. Diaoluo (Figures 1 and 3). This finding might be related with plant diversity because plant diversity in Mt. Diaoluo is higher than that in Mt. Jianfeng [28]. Secondly, AMF communities may not only be controlled by plant diversity but also by other characteristics of the plant community. Li et al. (2014) suggested that host identity is an important determinant for the structure of the AMF communities along the elevational gradients in high altitude environments [29]. Thirdly, AMF community diversity is regulated by multiple factors, such as all kinds of environmental factors [30]. Probably, the effects of environmental factors and 
host plants on AMF community diversity are also not accordant, which leads their impacts to be counteracted [31]. At the same time, the results that soil characteristics affect AMF community in this study further support the reason.

AMF OTU richness at all elevations in the two mountains with changes from 80 to 173 was more abundant than previous studies [29,30]. We propose the following reasons: (i) AMF diversity in a region was lower than the sum of different sites owing to the characteristics of low endemism [6]; (ii) it is possible that the diversity of AMF taxa is also higher in tropical forest than others ecosystems due to high plant diversity; (iii) illumina MiSeq sequencing has higher sequencing depth and throughput, higher-quality read cover, and a lower rate of erroneous sequences compared with previous molecular methods. Therefore, the finding of Davison et al. (2015) is consistent with our result with the mean of 66 AMF taxa in each site [6]. Meanwhile, AMF diversity quantified from DNA extracted from soil is higher than roots due to the fungal characteristics of non-obligate symbiosis with plant hosts. However, there are also conflicting reports [32]. Therefore, we consider two questions that should be explored for better explaining the result. Firstly, is to investigate the AMF OTU richness in plant roots in the present region. The second is to study the differences of AMF diversity between soil and root samples [33].

The effects of elevation on AMF diversity have been widely reported due to its importance in the diversity of plants and microorganisms. Our results suggest that elevation plays a negligible role in AMF community diversity in tropical forest of China, which might be explained by no detected trend of AMF diversity with the changes of elevations in different sites. AMF richness and diversity showed a significant negative correlation with altitude from a.s.l. 3320 up to $3800 \mathrm{~m}$ in South American Puna grassland [34]. Other studies also supported this conclusion of a decline in AMF species richness with increasing elevation [35].

CCA analysis showed that elevation and soil variables had variable effects on AMF community distribution in two mountains. Previous studies have also queried which soil variables have the greatest amount of contribution to the structure of an AMF community. For example, soil phosphorus is considered as a key role for AMF communities in lots of studies [36]. However, soil phosphorus did not play any significant role in the present study, which is consistent with some previous findings [37]. Therefore, in our opinion, it is worth studying further the effect of different environment factors on AMF communities in tropical forest.

When the genera of AMF taxa are considered, we find that Glomus is a dominant genus, which is in agreement with the results of other studies in arid areas [38]. This is possibly explained by broad ecological amplitude, ability for easy colonization, and easy propagation [27].

Author Contributions: Conceptualization, Z.S.; methodology, Z.S., F.W. and X.W.; software, Z.S. and W.Z.; validation, K.Y., and X.W.; formal analysis, Z.S.; investigation, Z.S., K.Y., F.W., X.W., W.Z. and Y.L.; writing一original draft preparation, Z.S.; writing-review and editing, Z.S., F.W. and B.S.M.; visualization, Z.S.; supervision, Z.S. and F.W.; project administration, Z.S.; funding acquisition, Z.S.

Funding: This research was funded by NSFC (31670499), Program for Science \& Technology Innovation Talents in Universities of Henan Province (18HASTIT013), Scientific and technological research projects in Henan province (192102110128), Key Laboratory of Mountain Surface Processes and Ecological Regulation, CAS (20160618), Laboratory for Earth Surface Processes, Ministry of Education (201612), the Innovation Team Foundation (2015TTD002) of Henan University of Science and Technology.

Conflicts of Interest: The authors declare no conflict of interest. The funders had no role in the design of the study; in the collection, analyses, or interpretation of data; in the writing of the manuscript, or in the decision to publish the results.

\section{References}

1. Smith, S.E.; Read, D.J. Mycorrhizal Symbiosis, 3rd ed.; Academic Press: Cambridge, UK, 2008; pp. 13-89.

2. Shi, Z.; Zhang, X.; Xu, S.; Lan, Z.; Li, K. Mycorrhizal relationship in lupines: A review. Legume Res. 2017, 40, 965-973. [CrossRef] 
3. van der Heijden, M.G.A.; Klironomos, J.N.; Ursic, M.; Moutoglis, P.; Streitwolf-Engel, R.; Boller, T.; Wiemken, A.; Sanders, I. Mycorrhizal fungal diversity determines plant biodiversity, ecosystem variability and productivity. Nature 1998, 396, 69-72. [CrossRef]

4. Jing, X.; Sanders, N.J.; Shi, Y.; Chu, H.; Classen, A.T.; Zhao, K.; Chen, L.; Shi, Y.; Jiang, Y.; He, J.S. The links between ecosystem multifunctionality and above-and belowground biodiversity are mediated by climate. Nat. Commun. 2015, 6, 8159. [CrossRef]

5. Bachelot, B.; Uriarte, M.; McGuire, K.L.; Thompson, J.; Zimmerman, J. Arbuscular mycorrhizal fungal diversity and natural enemies promote coexistence of tropical tree species. Ecology 2017, 98, 712-720. [CrossRef]

6. Davison, J.; Moora, M.; Öpik, M.; Adholeya, A.; Ainsaar, L.; Bâ, A.; Burla, S.; Diedhiou, A.G.; Hiiesalu, I.; Jairus, T.; et al. Global assessment of arbuscular mycorrhizal fungus diversity reveals very low endemism. Science 2015, 349, 970-973. [CrossRef]

7. Nasto, M.K.; Osborne, B.B.; Lekberg, Y.; Asner, G.P.; Balzotti, C.S.; Porder, S.; Taylor, P.G.; Townsend, A.R.; Cleveland, C.C. Nutrient acquisition, soil phosphorus partitioning and competition among trees in a lowland tropical rain forest. New Phytol. 2017, 214, 1506-1517. [CrossRef]

8. $\quad$ Liang, Z.B.; Lee, D.J.; Dweikat, I.M.; Wedin, D.A.; Yuen, G.Y.; Drijber, R.A. Molecular diversity of arbuscular mycorrhizae in roots of Juniperus virginiana invasive to grasslands. Soil Sci. Soc. Am. J. 2017, 81, 526-536. [CrossRef]

9. Shi, Z.; Chen, Y.; Hou, X.; Gao, S.; Wang, F. Arbuscular mycorrhizal fungi associated with tree peony in 3 geographic locations in China. Turk. J. Agric. For. 2013, 37, 726-733. [CrossRef]

10. Steidinger, B.S.; Crowther, T.W.; Liang, J.; van Nuland, M.E.; Werner, G.D.A.; Reich, P.B.; Nabuurs, G.J.; de-Miguel, S.; Zhou, M.; Picard, N.; et al. Climatic controls of decomposition drive the global biogeography of forest-tree symbioses. Nature 2019, 569, 404. [CrossRef]

11. Santiago, L.S. Nutrient limitation of eco-physiological processes in tropical trees. Trees 2015, 29, 1291-1300. [CrossRef]

12. Averill, C.; Turner, B.L.; Finzi, A.C. Mycorrhiza-mediated competition between plants and decomposers drives soil carbon storage. Nature 2014, 505, 543-545. [CrossRef]

13. Camenzind, T.; Homeier, J.; Dietrich, K.; Hempel, S.; Hertel, D.; Krohn, A.; Leuschner, C.; Oelmann, Y.; AxelOlsson, P.; Suárez, J.P.; et al. Opposing effects of nitrogen versus phosphorus additions on mycorrhizal fungal abundance along an elevational gradient in tropical montane forests. Soil Biol. Biochem. 2016, 94, 37-47. [CrossRef]

14. Alexander, I.; Selosse, M.A. Mycorrhizas in tropical forests: A neglected research imperative. New Phytol. 2009, 182, 14-16. [CrossRef]

15. Vieira, L.C.; da Silva, D.K.A.; da Silva, I.R.; Gonçalves, C.M.; de Assis, D.M.A.; Oehl, F.; da Silva, G.A. Ecological aspects of arbuscular mycorrhizal fungal communities in different habitat types of a Brazilian mountainous area. Ecol. Res. 2019, 34, 182-192. [CrossRef]

16. Vieira, L.C.; da Silva, D.K.A.; de Melo, M.A.C.; Escobar, I.E.C.; Oehl, F.; da Silva, G.A. Edaphic factors influence the distribution of arbuscular mycorrhizal fungi along an altitudinal gradient of a tropical mountain. Microb. Ecol. 2019, 1-10. [CrossRef]

17. Wagg, C.; Husband, B.C.; Green, D.S.; Massicotte, H.B.; Peterson, R.L. Soil microbial communities from an elevational cline differ in their effect on conifer seedling growth. Plant Soil 2011, 340, 491-504. [CrossRef]

18. Bryant, J.A.; Lamanna, C.; Morlon, H.; Kerkhoff, A.J.; Enquist, B.J.; Green, J.L. Microbes on mountainsides: Contrasting elevational patterns of bacterial and plant diversity. Proc. Natl. Acad. Sci. USA 2008, 105, 11505-11511. [CrossRef]

19. Chatterjee, A.; Lal, R.; Wielopolski, L.; Martin, M.Z.; Ebinger, M.H. Evaluation of Different Soil Carbon Determination Methods. Crit. Rev. Plant Sci. 2009, 28, 164-178. [CrossRef]

20. Zobeck, T.M.; Baddock, M.; Van Pelt, R.S.; Tatarko, J.; Acosta-Martinez, V. Soil property effects on wind erosion of organic soils. Aeolian Res. 2013, 10, 43-51. [CrossRef]

21. Wang, H.M.; Wang, W.J.; Chen, H.; Zhang, Z.; Mao, Z.; Zu, Y.G. Temporal changes of soil physic-chemical properties at different soil depths during larch afforestation by multivariate analysis of covariance. Ecol. Evol. 2014, 4, 1039-1048. [CrossRef]

22. Uparse OUT Clustering. Available online: http://drive5.com/uparse/ (accessed on 8 May 2019).

23. RDP Classifier Algorithm. Available online: http://rdp.cme.msu.edu/ (accessed on 18 April 2019). 
24. Jin, Y.; Liu, Y.; Zhao, L.; Zhao, F.; Feng, J.; Li, S.; Chen, H.; Sun, J.; Zhu, B.; Geng, R.; et al. Gut microbiota in patients after surgical treatment for colorectal cancer. Environ. Microbiol. 2019, 21, 772-783. [CrossRef]

25. Xiong, W.; Zhao, Q.Y.; Xue, C.; Xun, W.B.; Zhao, J.; Wu, H.S.; Li, R.; Shen, Q.R. Comparison of Fungal Community in Black Pepper-Vanilla and Vanilla Monoculture Systems Associated with Vanilla Fusarium Wilt Disease. Front. Microbiol. 2016, 7, 117. [CrossRef]

26. Majorbio. Available online: www.i-sanger.com/ (accessed on 16 June 2019).

27. Öpik, M.; Zobel, M.; Cantero, J.J.; Davison, J.; Facelli, J.M.; Hiiesalu, I.; Jairus, T.; Kalwij, J.M.; Koorem, K.; Leal, M.E.; et al. Global sampling of plant roots expands the described molecular diversity of arbuscular mycorrhizal fungi. Mycorrhiza 2013, 2, 411-430. [CrossRef]

28. Qiu, Z.J.; Qiu, J.R.; Zhou, G.Y.; Liu, H.W.; Li, G.M. Comparative analysis of meteorological elements between Hainan's Diaoluoshan and Jiangfengling tropical forest region. Ecol. Sci. 2004, 23, 338-341.

29. Li, X.; Gai, J.; Cai, X.; Li, X.; Christie, P.; Zhang, F.; Zhang, J. Molecular diversity of arbuscular mycorrhizal fungi associated with two co-occurring perennial plant species on a Tibetan altitudinal gradient. Mycorrhiza 2014, 24, 95-107. [CrossRef]

30. Liu, M.; Zheng, R.; Bai, S.; Bai, Y.; Wang, J. Slope aspect influences arbuscular mycorrhizal fungus communities in arid ecosystems of the Daqingshan Mountains, Inner Mongolia, North China. Mycorrhiza 2017, 27, 189-200. [CrossRef]

31. Gai, J.P.; Tian, H.; Yang, F.Y.; Christie, P.; Li, X.L.; Klironomosa, J.N. Arbuscular mycorrhizal fungal diversity along a Tibetan elevation gradient. Pedobiologia 2012, 55, 145-151. [CrossRef]

32. Schappe, T.; Albornoz, F.E.; Turner, B.L.; Neat, A.; Condit, R. The role of soil chemistry and plant neighbourhoods in structuring fungal communities in three Panamanian rainforests. J. Ecol. 2017, 105, 569-579. [CrossRef]

33. Mickan, B.S.; Hart, M.M.; Solaiman, Z.M.; Jenkins, S.; Siddique, K.H.; Abbott, L.K. Molecular divergence of fungal communities in soil, roots and hyphae highlight the importance of sampling strategies. Rhizosphere 2017, 4, 104-111. [CrossRef]

34. Lugo, M.A.; Ferrero, M.; Menoyo, E.; Estévez, M.C.; Siñeriz, F.; Anton, A. Arbuscular mycorrhizal fungi and rhizospheric bacteria diversity along an altitudinal gradient in South American Puna Grassland. Microb. Ecol. 2008, 55, 705-713. [CrossRef]

35. Egan, C.P.; Callaway, R.M.; Hart, M.M.; Pither, J.; Klironomos, J. Phylogenetic structure of arbuscular mycorrhizal fungal communities along an elevation gradient. Mycorrhiza 2017, 27, 273-282. [CrossRef] [PubMed]

36. Ji, B.; Bever, J.D. Plant preferential allocation and fungal reward decline with soil phosphorus enrichment: Implications for evolution of the arbuscular mycorrhizal mutualism. Ecosphere 2016, 7, e01256. [CrossRef]

37. Moora, M.; Davison, J.; Öpik, M.; Metsis, M.; Saks, Ü.; Jairus, T.; Vasar, M.; Zobel, M. Anthropogenic land use shapes the composition and phylogenetic structure of soil arbuscular mycorrhizal fungal communities. FEMS Microbiol. Ecol. 2014, 90, 609-621. [CrossRef] [PubMed]

38. da Silva, I.R.; de Mello, C.M.A.; Neto, R.A.F.; da Silva, D.K.A.; de Melo, A.L.; Oehl, F.; Costa Maia, L. Diversity of arbuscular mycorrhizal fungi along an environmental gradient in the Brazilian semiarid. Appl. Soil Ecol. 2014, 84, 166-175. [CrossRef]

(C) 2019 by the authors. Licensee MDPI, Basel, Switzerland. This article is an open access article distributed under the terms and conditions of the Creative Commons Attribution (CC BY) license (http://creativecommons.org/licenses/by/4.0/). 